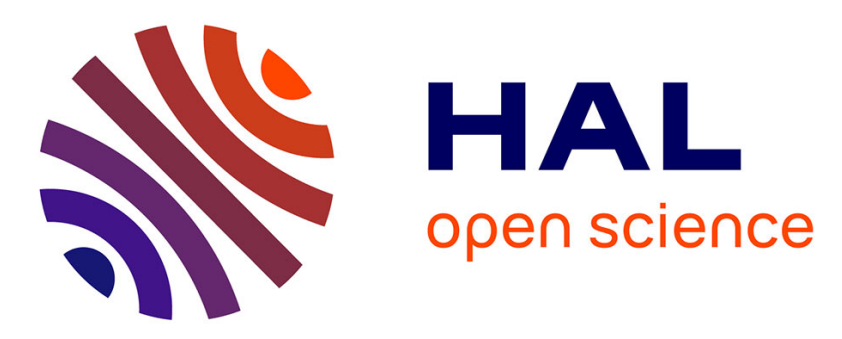

\title{
LiFi Reception from Organic Photovoltaic Modules Subject to Additional DC Illuminations and Shading
} Effects

\author{
N Lorrière, Gilles Chabriel-, Jean Barrère, M. Pasquinelli, G Pic, N \\ Vannieuwenhuyse, Ludovic Escoubas, J.-J Simon
}

\section{To cite this version:}

N Lorrière, Gilles Chabriel-, Jean Barrère, M. Pasquinelli, G Pic, et al.. LiFi Reception from Organic Photovoltaic Modules Subject to Additional DC Illuminations and Shading Effects. 2019 Global LIFI Conbgress (GLC), Jun 2019, Paris, France. hal-02178251

\section{HAL Id: hal-02178251 \\ https://hal.science/hal-02178251}

Submitted on 9 Jul 2019

HAL is a multi-disciplinary open access archive for the deposit and dissemination of scientific research documents, whether they are published or not. The documents may come from teaching and research institutions in France or abroad, or from public or private research centers.
L'archive ouverte pluridisciplinaire HAL, est destinée au dépôt et à la diffusion de documents scientifiques de niveau recherche, publiés ou non, émanant des établissements d'enseignement et de recherche français ou étrangers, des laboratoires publics ou privés. 


\title{
LiFi Reception from Organic Photovoltaic Modules Subject to Additional DC Illuminations and Shading Effects
}

\author{
N. Lorrière, G. Chabriel, J. Barrère, M. Pasquinelli, G. Pic, N. Vannieuwenhuyse, L. Escoubas and J.-J. Simon
}

\begin{abstract}
In this paper, we study the performance of organic photovoltaic (OPV) modules as $\mathrm{LiFi}$ receivers in two specific configurations. The $\mathrm{PV}$-based $\mathrm{LiFi}$ receiver is first exposed to an additional homogeneous light source with different intensity levels and then the influence of partial lighting is studied (shading effect). In both cases, we compare the sensibility and the cutoff frequency of LiFi transmission when the solar cell is operated either in short- circuit mode (i.e. when it is loaded with an active transimpedance amplifier) or in open circuit mode (i.e. when it is terminated with an high impedance passive load). While the OPV module performance decreases in open-circuit mode as a function of the DC illumination level, we observe an improvement of the cutoff frequency in short circuit mode. This result seems very promising for outdoor $\mathrm{LiFi}$ transmissions but also for indoor conditions where natural light can disturb LiFi communications. Theoretical explanations involving physical parameters for energy harvesting (carrier mobility, lumped series resistance) are proposed to justify the observed behaviors. Finally, experimental results of shaded solar cells are provided in the two operating modes (open-circuit and short-circuit). We show that sensibility and bandwidth of OPV modules strongly depend on both the shading configuration and the operating mode.
\end{abstract}

\section{INTRODUCTION}

The possibility of using photovoltaic (PV) modules for visible light communications (VLC) is still relatively new [1]-[5] and the main expected benefits are to ideally obtain a self-supplied $\mathrm{LiFi}$ receiver [6], [7] operating outside and coupled with a large and flexible reception area. Remarkably, the use of organic solar cells as receiver for VLC has been demonstrated [4]. The latest performance of the commercially available ARMOR's OPV modules named ASCA® [8], allows to further investigate the behavior of such technology. Therefore, the large scale availability of this third generation of PV technology is paving the way of future printed eco-friendly VLC systems.

Some studies propose to use the PV cells left open-circuit (at least from a dynamic point of view) and one talks about open-circuit voltage $\left(V_{o c}\right)$ operating mode. In this paper, we propose to provide performance results when the PV module

N. Lorrière, M. Pasquinelli, L. Escoubas and J.-J. Simon are with Aix Marseille Univ, Univ Toulon, CNRS, IM2NP, Marseille, France (e-mail: nominoe.lorriere@im2np.fr; marcel.pasquinelli@univ-amu.fr; ludovic.escoubas@univ-amu.fr; jean-jacques.simon@univ-amu.fr).

G. Chabriel and J. Barrère are with Univ Toulon, Aix Marseille Univ, CNRS, IM2NP, La Garde, France (e-mail: gilles.chabriel@im2np.fr; jean.barrere@im2np.fr).

G. Pic and N. Vannieuwenhuyse are with ARMOR SAS company, La Chevrolière, France (e-mail: guillaume.pic@armor-group.com; nicolas.vannieuwenhuyse@armor-group.com). is "shortcircuited" i.e when it is loaded by a transimpedance amplifier. We use the term: short-circuit current $\left(I_{s c}\right)$ operating mode. Advantages of the $I_{s c}$ operating mode ( $v s$. the $V_{o c}$ one) for higher data rate transmission are emphasized. Measurements of organic PV module efficiency under realistic outdoor conditions are provided. In particular, results about the impact of global and local irradiance [9], [10] over the frequency response (gain and bandwidth) of a PV-based LiFi receiver are discussed for the two operating modes.

Moreover, since a PV module offers a large detection surface, its behavior in response to a partial shadowing has to be explored. We show that shadowing influence is highly dependent of the operating mode and the shadow direction.

\section{MODELING}

I(V) characteristics of organic photovoltaic cells can be modeled in the same way as well-known inorganic cells. Indeed, the charge Density Of State (DOS) between HOMO and LUMO states is distributed exponentially [11], [12] just as minority carrier on valence and conduction bands. Thus, in DC we consider that the relation between the output current $I_{s}$ and the output voltage $V_{\text {out }}$ is defined by the transcendental equation:

$$
I_{s}=I_{p h}-I_{0}\left[\exp \left(\frac{V_{\text {out }}+I_{s} R_{s}}{n \frac{k T}{q}}\right)-1\right]-\frac{V_{\text {out }}+I_{s} R_{s}}{R_{s h}}
$$

with $I_{p h}$ the photogenerated current, $I_{0}$ the dark saturation current and $\frac{k T}{q}=V_{T}$ the thermal voltage.

The following figure Fig. 1 represents the classical linearized AC model corresponding to a forward biased solar cell.

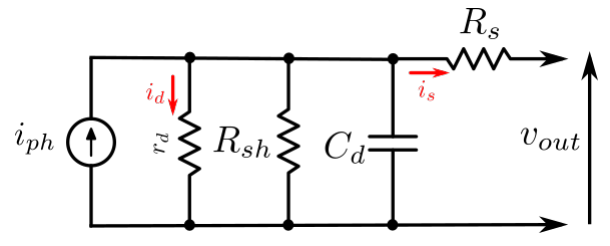

Fig. 1. PV cell AC low variations equivalent circuit

In this equivalent circuit, $r_{d}$ is the dynamic resistance, $R_{s h}$ the shunt resistance, $C_{d}$ the diffusion capacitance and $R_{s}$ is the lumped series resistance. Finally, $i_{p h}$ corresponds to the variations of the photocurrent. 


\section{A. $V_{\text {oc }}$ operating mode}

When the output of the solar cell is left open (or loaded by a sufficiently high impedance), since $i_{s} \approx 0$, the effect of the series resistance $R_{s}$ can be neglected. Moreover, since a high DC current passes through the solar cell $\left(I_{d} \approx I_{p h}\right)$, one can consider from

$$
r_{d}=\frac{n V_{T}}{I_{p h}}
$$

that the dynamic resistance is sufficiently low so that $R_{s h}$ can be neglected. Now, using

$$
C_{d}=\frac{\tau}{r_{d}},
$$

where $\tau$ represents the charge carrier lifetime, one obtains the following complex transfer function:

$$
T_{o c}(s) \triangleq \frac{v_{o u t}(s)}{i_{p h}(s)} \triangleq \frac{v_{o c}(s)}{i_{p h}(s)}=\frac{r_{d}}{1+\tau s} .
$$

It corresponds to a first-order low-pass filter where the static gain $r_{d}=\frac{n V_{T}}{I_{p h}}$ is expected to decrease with the DC illumination $I_{p h}$ (and to increase with the temperature). At contrast, since the charge carrier lifetime $\tau$ generally decreases with the DC illumination, the $-3 \mathrm{~dB}$ cutoff frequency $f_{c}=\frac{1}{2 \pi \tau}$ is expected to increase with the DC component of the photocurrent.

\section{B. $I_{s c}$ operating mode}

To use a solar cell in $I_{s c}$ operating mode, the cell has to feed the input of a transimpedance amplifier (TIA) as illustrated on the following figure Fig. 2,

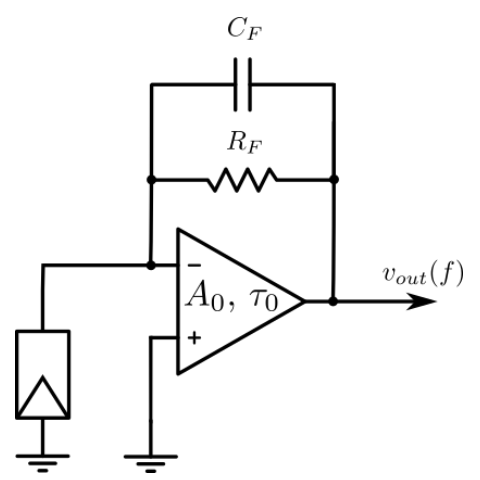

Fig. 2. $I_{s c}$ operating mode PV cell

where the operational amplifier (OPA) is modeled by its differential gain $A_{0}$ and its open-loop cutoff frequency: $\frac{1}{2 \pi \tau_{0}}$.

Since the OPA maintains a very low forward bias at the output of the solar cell, a very small portion of the DC current passes through the solar cell (say $I_{d}=\varepsilon I_{p h}$, where $\varepsilon \ll 1$ ). Consequently, the dynamic resistance $r_{d}$ becomes high and can then be neglected compared to $R_{s h}$. Some mathematical derivations lead to the following three-order low-pass filter expression of the complex transfer function:

$$
\begin{aligned}
T_{s c}(s) & \triangleq \frac{v_{\text {out }}(s)}{i_{\text {ph }}(s)} \\
& =\frac{A_{0} Z_{i}(s) Z_{F}(s)}{\left(A_{0}+1+\tau_{0} s\right)\left(R_{s}+Z_{i}(s)\right)+\left(1+\tau_{0} s\right) Z_{F}(s)}
\end{aligned}
$$

where $Z_{i}(s)=\frac{1}{C_{d} s} \| R_{s h}$ and $Z_{F}(s)=\frac{1}{C_{F} s} \| R_{F}$.

A rapid study shows that the static gain corresponds to the feedback resistance $R_{F}$. It is then independent of the PV cell characteristics and therefore not linked to the DC injection level. Additionally, it can be shown that the maximum achievable cutoff frequency is $f_{c}=\frac{1}{2 \pi R_{s} C_{d}}$. From (2) and (3), it comes

$$
f_{c} \propto \frac{n V_{T}}{R_{s} \varepsilon I_{p h} \tau} .
$$

In the above expression (6) of the maximum cutoff frequency, the DC current $I_{p h}$ appears in the denominator of the ratio and then tends to fall the cutoff frequency if it increases. Simultaneously, both the lumped series resistance $R_{s}$ and the charge carrier lifetime $\tau$ tend to decrease with the injection level $I_{p h}$. Futher studies will be required to verify the variation of the cut-off frequency with DC illumination (the influence of temperature should also be considered).

\section{EXPERIMENTAL SETUP}

All the experimental frequency responses provided in this study were obtained using the OFDM (orthogonal frequencydivision multiplexing) testbench developed at IM2NP lab. and described in [13].

The hardware consists, for the transmitter part, in a Philips Lumileds one High Power LED referenced as Luxeon Rebel Plus LX18-P140-Y. For the receiver part, we use an ASCA ${ }^{\circledR}$ organic PV module designed by ARMOR company (Fig. 3). It is composed of 9 cells all connected in series to exhibit an open circuit voltage of $7.28 \mathrm{~V}$ and a short circuit current of $33.75 \mathrm{~mA}$ at AM1.5 condition. The Transmitter/Receiver distance is set to obtain a 450 lux lighting at the LED maximum level illumination point. The data acquisition (AD conversion) is performed using a MDO3034 Tektronix oscilloscope and controlled by a MATLAB 2017b interface. For $I_{s c}$ mode measurements, a Stanford Research SR570 preamplifier (TIA) is added to convert the current provided by the module to a voltage suitable to the oscilloscope.

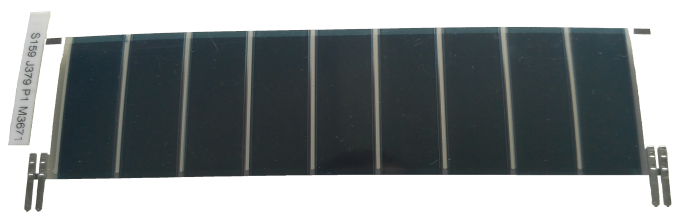

Fig. 3. ASCA® OPV module 
The unipolar scheme chosen for the optical transmission is the classical DCO-OFDM (direct current biased optical OFDM) [14], [15]. Within each sent OFDM symbol, the $K$ payload subcarriers $k \Delta_{f}\left(1 \leq k \leq K, \Delta_{f}=\frac{F_{\max }}{2(K+1)}\right)$, are phase-modulated by complex data extracted from a QPSK alphabet. Each symbol is extended by a cyclic prefix (CP) with a duration $T_{c p}$. The cyclic prefix duration $T_{c p}$ has to be greater than the transient response duration of the channel in order to reach the steady-state regime. Here, $T_{c p}$ is chosen equal to the OFDM symbol duration i.e. $\frac{1}{\Delta_{f}}$.

From $K$ known transmitted data, averaging over $M$ OFDM symbols and assuming a linear transmission channel, the orthogonal frequency modulation scheme allows to easily estimate, in one shot, the complex frequency response of the channel from the emitting LED (exhibiting a flat channel at considered frequencies) to the PV receiver for the whole subcarrier frequencies.

In this study, we get : $K=255, M=975$ and $F_{\max }=250 \mathrm{kHz}$ (resp. $50 \mathrm{kHz}$ ) for the $I_{s c}$ mode (resp. for the $V_{o c}$ mode). For example, in the $I_{s c}$ mode, frequencies from $\Delta_{f}=\frac{F_{\max }}{2(K+1)}=488.3 \mathrm{~Hz}$ to $K \Delta_{f}=124.5 \mathrm{kHz}$ are scanned in $2 \times \frac{M}{\Delta_{f}} \approx 4 \mathrm{~s}$.

Obviously, the absolute value of the frequency response is not available. The provided gain frequency responses then have to be interpreted in a relative way from an experiment to another; the experimental conditions being maintained as closely as possible. Thus, since the two PV operating modes lead to two different experimental setups, the $I_{s c}$ and $V_{o c}$ measurements cannot be compared with each other.

\section{RESUlts}

\section{A. Influence of solar cell operating mode on the cut-off frequency}

1) $V_{\text {oc }}$ operating mode: Fig. 4 provides the evolution of the gain frequency response for different values of the additional DC illumination level from 450 to 5500 lux.

As the DC level increases, it can be observed, as expected, an important diminution of the static gain $T_{o c}$ because $r_{d} \propto$ $\frac{1}{I_{p h}}$ (see Fig. 5 for a log-linear representation) and an increase of the frequency bandwidth $f_{c} \propto \frac{1}{\tau}$.

As a consequence, in a $V_{o c}$ mode transmission context, the signal-to-noise ratio (SNR) is expected to degrade as the DC illumination level increases.

2) $I_{s c}$ operating mode: Fig. 6 shows the evolution of the gain frequency response for different values of the additional DC illumination level when LiFi communication is performed in $I_{s c}$ mode. Unlike Fig. 4, we can first observe that the static gain remains constant as expected by modeling. A slight increase of the cutoff frequency is also observed as the DC light level rises. The diminution of both the series resistance $R_{s}$ and the charge carrier lifetime $\tau$ could compensate the increase of the DC current $I_{p h}$ in the denominator of the expression of the cutoff frequency (6).

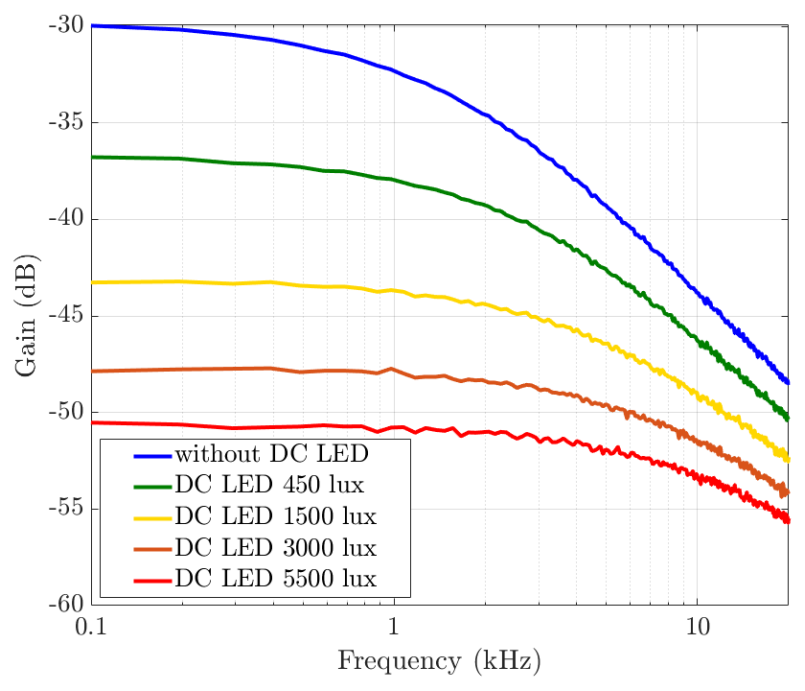

Fig. 4. Frequency response in $V_{o c}$ operating mode

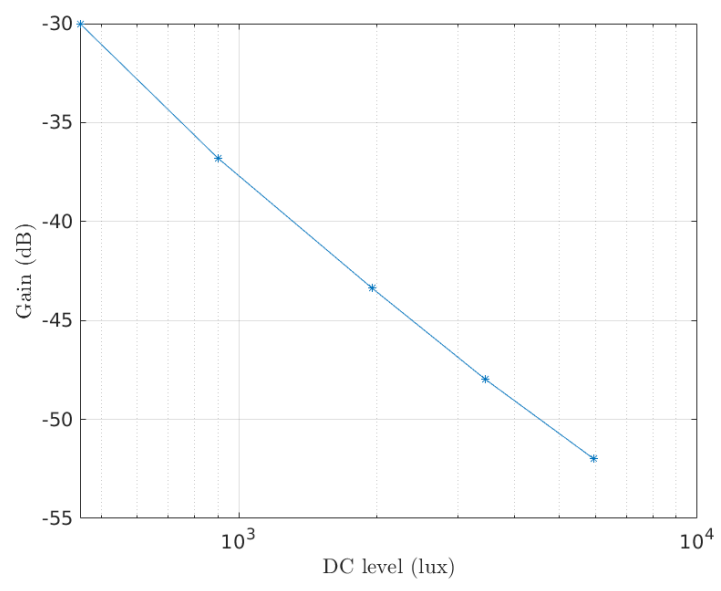

Fig. 5. Static gain vs. DC level in $V_{o c}$ operating mode

In addition to the non-sensitivity of the frequency response to DC illumination, it is important to note that without DC LED, the cutoff frequency on $I_{s c}$ mode $(66.4 \mathrm{kHz})$ is 50 times higher than that on $V_{o c}$ mode $(1.3 \mathrm{kHz})$. SNR measurements should help to confirm the net benefit of switching to $I_{s c}$ mode.

\section{B. Shading effects}

In this section, frequency responses are provided when the $110 \mathrm{~mm} \times 52 \mathrm{~mm}$ area ASCA ${ }^{\circledR}$ OPV module is partially shaded in the lateral or longitudinal direction as illustrated on Fig. 7. 


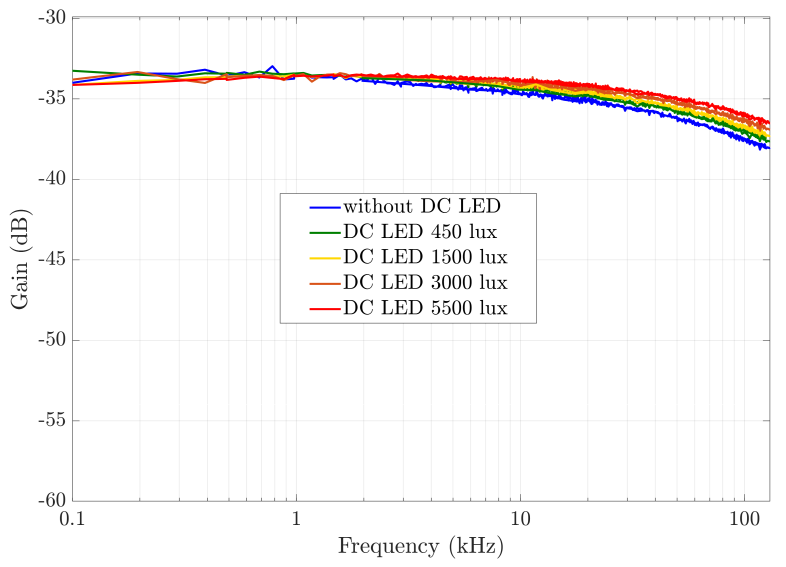

Fig. 6. Frequency response in $I_{s c}$ operating mode

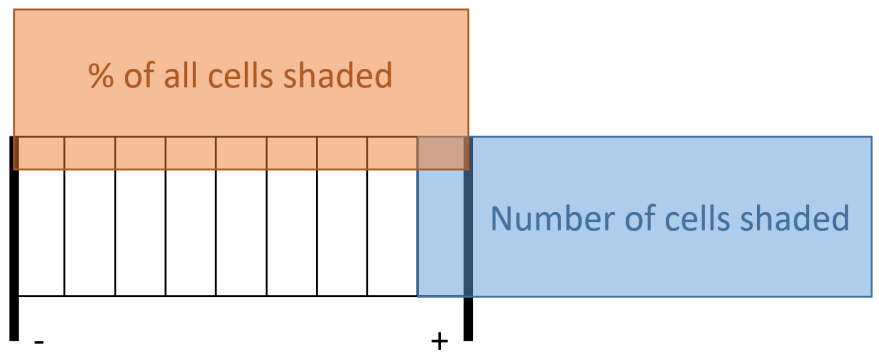

Fig. 7. Directions of shading

The shading effects are explored in each direction and for each operating mode. The results are presented in the following four figures (from Fig. 8 to Fig. 11).

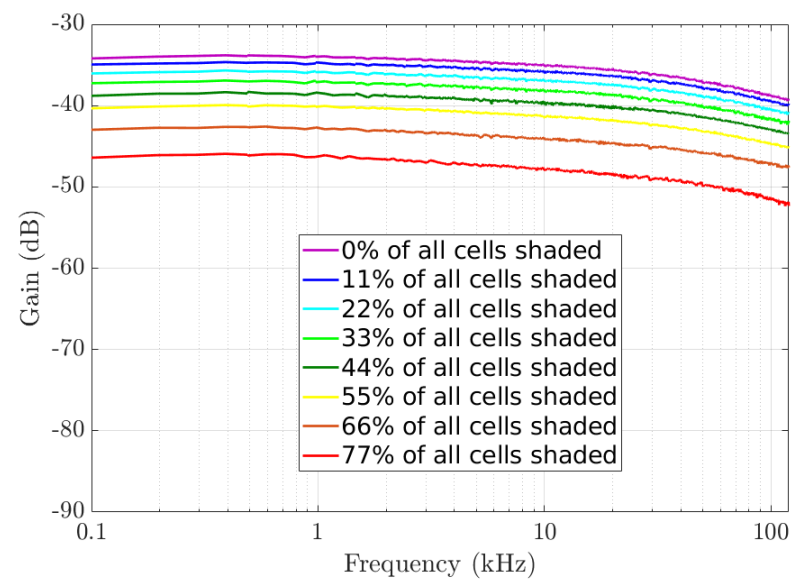

Fig. 8. $I_{s c}$ condition - Shading direction "\% of all cells shaded"

It is well known [16], [17] that the two shading directions generally induce very different behaviors: when all the cells

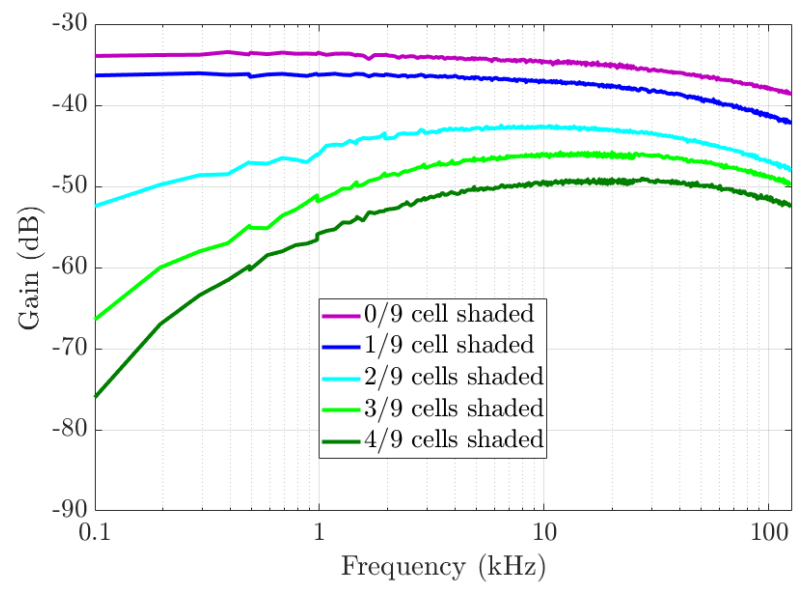

Fig. 9. $I_{s c}$ condition - Shading direction "Number of cells shaded"

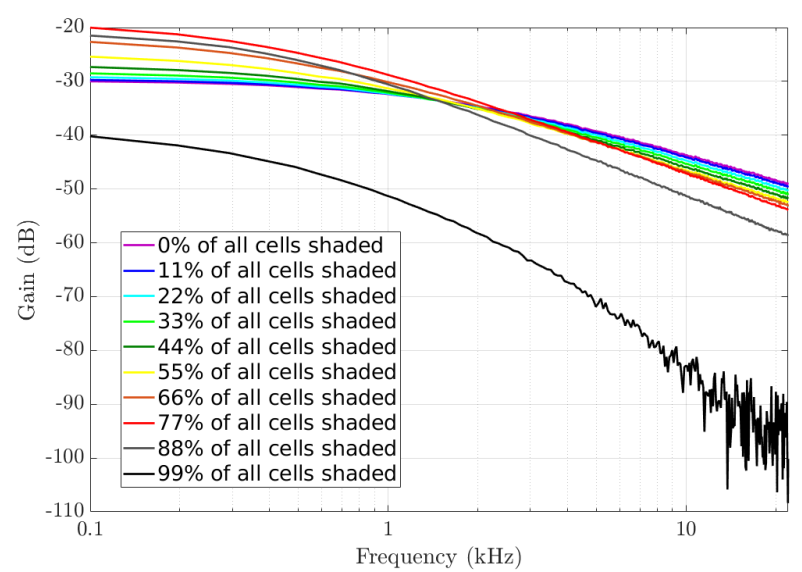

Fig. 10. $V_{o c}$ condition - Shading direction "\% of all cells shaded"

are partially shaded, it can be considered that it is just a PV module with a smaller active surface. When one or more cells are fully hidden, these non-illuminated cells act as impedance loads for the cells remained active. It is then clear that the shading location will differently impact the frequency responses according to the operating mode used:

- In short-circuit mode, since the amount of the received photocurrent $i_{p h}$ decreases, the output voltage $R_{f} i_{p h}$ will decrease when all cells are more and more hidden (Fig. 8).

A high-pass filtering effect is observed (Fig. 9) when one or several cells are fully shadowed. This phenomenon is due to the shaded cells capacities in series acting as very high impedances for low frequency photocurrents. Moreover, the photocurrent $i_{p h}$ being generated by the only exposed cells, a general attenuation is observed. 


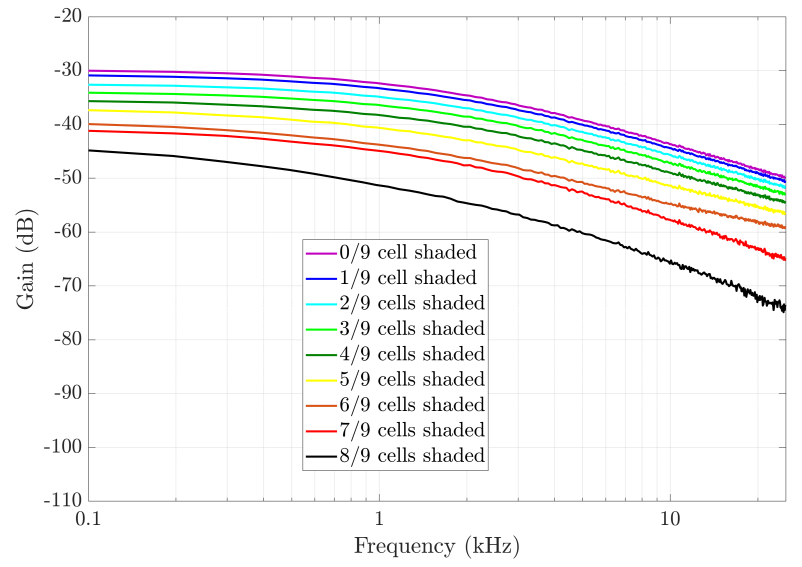

Fig. 11. $V_{o c}$ condition - Shading direction "Number of cells shaded"

- In open-circuit mode, when all the cells are partially shadowed, the DC photocurrent $I_{p h}$ being weaker, the static gain (resistance $r_{d}$ ) tends to highly increase (non-linear behavior) and consequently tends to overcompensate the diminution of the dynamic photocurrent $i_{p h}$. In the same time, the carrier lifetime increases (less available holes in the structure) and then diminishes the cutoff frequency. A higher voltage is then observed at low frequencies (Fig. 10).

When some cells are fully shadowed, most of the photocurrent is now absorbed by the non-illuminated cells. The modulus of these impedance loads $\left(R_{s h} \| C_{d}\right)$ decreasing with the frequency and decreasing when more and more cells are hidden, a diminution of both the static gain and the cutoff frequency is then observed (Fig. 11).

Generally, for shaded PV modules operating in the $V_{o c}$ mode, the output voltage decreases but not in the same degree as in the $I_{s c}$ mode. It can be explained by the increase of the static gain $\left(r_{d}\right)$ witch is always constant $\left(R_{f}\right)$ in the $I_{s c}$ mode.

\section{CONCLUSION AND PERSPECTIVES}

In this paper, we study in a first part the dynamic behavior of OPV modules as a function of the DC photocurrent for two operating modes: the $V_{o c}$ mode and the $I_{s c}$ mode. We show that in the $V_{o c}$ mode, the static gain diminishes with the DC illumination while the frequency bandwidth increases. A higher bandwidth is obtained in the $I_{s c}$ mode and both the static gain and the frequency bandwidth are a priori not impacted by an additional DC irradiation. This last result is encouraging for the use of PV modules as outdoor LiFi receiver and even more for mixed indoor/outdoor conditions. In a second part, we study the resilience of the two operating modes to shading effects. We have observed that the decrease of the static gain is more important in the $I_{s c}$ mode than in the $V_{o c}$ mode.
Finally, the $I_{s c}$ operating mode would allow to reach a better data rate than in the $V_{o c}$ mode but shading effects would impact the performance. Complementary SNR measurements are in progress to confirm such important results.

\section{REFERENCES}

[1] S.-M. Kim and J.-S. Won, "Simultaneous Reception of Visible Light Communication and Optical Energy using a Solar Cell Receiver", 2013 IEEE International Conference on Information and Communication Technology Convergence, Jeju Island (South Korea), 2013.

[2] Z. Wang, D. Tsonev et al., "On the Design of a Solar-Panel Receiver for Optical Wireless Communications With Simultaneous Energy Harvesting", IEEE Journal on Selected Areas in Communications, vol. 33(8) , pp. 1612 - 1623, 2015.

[3] E. Bialic, L. Maret et al., "Specific innovative semi-transparent solar cell for indoor and outdoor LiFi applications", Applied Optics, vol. 54 No. 27, pp. 8062-8069, 2015.

[4] S. Zhang, D. Tsonev et al., "Organic solar cells as high-speed data detectors for visible light communication", Optica Lett, vol. 2 No. 7, pp. 607-610, 2015.

[5] K. Sindhubala and B. Vijayalakshmi, "Receiver Intend to Reduce Ambient Light Noise in Visible-Light Communication using Solar Panels", Journal of Engineering Science and Technology Review, vol. 10 No. 1, pp. 84-90, 2017.

[6] "IEEE Standard for Local and Metropolitan Area Networks, Part 15.7: Short-Range Wireless Optical Communication Using Visible Light," IEEE Std.802.15.7, September 2011.

[7] H. Haas, "Wireless Data from Every Light Bulb", TED Website, August 2011.

[8] ARMOR ASCA®, 2019. URL: https://www.asca.com (online on 04/15/2019).

[9] M.S. Islim, S. Videv et al., "The Impact of Solar Irradiance on Visible Light Communications", Journal of Lightwave Technology, vol. 36 No. 12, pp. 2376-2386, 2018.

[10] M.S. Islim and H. Haas, "An Investigation of the Solar Irradiance Effect on Visible Light Communications", 2017 IEEE 28th Annual International Symposium on Personal, Indoor, and Mobile Radio Communications (PIMRC), Montreal, pp. 1-6, 2017.

[11] H. Bässler and A. Köhler, "Charge Transport in Organic Semiconductors", Topics in Current Chemistry, vol.312, pp. 1-66, 2012.

[12] R. Clerc, B. Bouthinon et al. "Current status and challenges of the modeling of organic photodiodes and solar cells", International Electron Device Meeting, San Francisco, United States, 2016.

[13] N. Lorrière, E. Bialic et al. "An OFDM Testbed for LiFi Performance Characterization of Photovoltaic Modules", Global LiFi Congress (GLC), Paris, 2018.

[14] S.D. Dissanayake and J. Armstrong, " Comparison of ACO-OFDM, DCO-OFDM and ADO-OFDM in IM/DD Systems", Journal of Lightwave Technology, vol. 31(7), pp. 1063-1072, 2013.

[15] M.S. Islim and H. Haas, "Modulation Techniques for Li-Fi", ZTE Communications Special issue on Multi-Gigabit Millimeter-Wave Wireless Communications, vol. 14(2), pp. 29-40, 2016.

[16] R.M. Sullivan "Shadow effects on a series-parallel array of solar cells", NASA Technical Report, Goddard Space Flight Center, Greenbelt, Maryland, United State, 1965.

[17] J. Hofer, A. Groenewolt et al., "Parametric analysis and systems design of dynamic photovoltaic shading modules", Energy Science and Engineering 2016, 4(2), pp. 134-152. 